\title{
IMPROVEMENT OF HOT LABORATORY FACILITIES IN NUCLEAR MEDICINE
}

\author{
Kamila Afroj Quadir ${ }^{1}$, Nurjahan Khatun ${ }^{1}$, Md. Ashraful Hoque ${ }^{2}$ and Aleya Begum ${ }^{2}$ \\ ${ }^{1}$ Institute of Nuclear Medicine \& Ultrasound, Bangladesh Atomic Energy Commission, Shahbagh, Dhaka 1000, \\ ${ }^{2}$ Health Physics Division, Bangladesh Atomic Energy Commission, Dhaka, Bangladesh. \\ email: q.kamila@gmail.com
}

\begin{abstract}
A Hot-Lab is the major source of radiation exposure by medical technicians in a nuclear medicine set up. A table top bench shield is used to reduce this exposure which consists of a lead base and a lead wall in the bottom part while a viewing window is provided in the top part through the use of thick glass or leaded glass. In our laboratory, a home-made shield was used earlier which incorporated a $254 \mathrm{~mm}$ ordinary glass window in the top and a thick lead wall at the bottom part. Recently a commercial bench shield was procured that uses a lighter lead glass window for better viewing. This lead glass gives an equivalent lead thickness of $2.2 \mathrm{~mm}$. The present work was taken up to study the changes in the radiation exposure to nuclear medicine technicians due to this change in the bench shield. The effective doses received by two technicians were $0.937 \mathrm{mSv}$ and $1.098 \mathrm{mSv}$ respectively when they worked for two months using the old table top bench shield. This dose came down substantially to $0.292 \mathrm{mSv}$ and $0.187 \mathrm{mSv}$ respectively, when they used the new table top bench shield for the same period of time. Side by side, the radiation reaching the outer surfaces of the glass shield and the lead wall were measured due to a radiation source placed at $0 \mathrm{~mm}, 10 \mathrm{~mm}$ and $20 \mathrm{~mm}$ from the respective inner surfaces. For the lead shield the dose rates were not much different between the two models, but for the glass window, the commercial one gave much reduced dose rate. Although the dosage was higher in the indigenously made device, the duty schedules of the technicians were rotated so that none received dosage greater than safe limits over a full year.
\end{abstract}

\section{Introduction}

The term 'hot-laboratory' (hot-lab) is used to describe the facility where large quantities of volatile radioisotopes such as, unsealed sources of ionizing radiation and generators, are handled. Usually this is done in a small side room off a main laboratory. This is where all the radioactive work in a nuclear medicine department takes place. Hot-lab is an exclusively reserved facility which is designated as a controlled area [1-3].

Persons working with unsealed radioactive sources must be protected not only from radiation emitted by the sources but also from ingestion, absorption or inhalation of radioactive material. Procedures to minimize the intake of radioactive nuclides into the body depend on the facilities available within an institution and vary from one institution to another. Guidelines for the safe use of radioactive materials are included in publications by individuals [4] and by advisory groups such as the ICRP and NCRP $[5,6]$.

The processing and analysis of highly radioactive substances and component materials requires sophisticated and extensive laboratory infrastructure that ensures safety and security, as well as a well educated scientific/technical personnel who can optimally and reliably use the facilities. The sources of ionizing radiation exposure should be handled on a "As Low As Reasonably Achievable" (ALARA) basis and for that every reasonable effort to maintain exposures to ionizing radiation below the dose limits [7] should be made by improving the hot-lab facility.

A table top bench shield was made indigenously earlier for the 'hot-lab' of our department where the radiation workers of nuclear medicine dispense and prepare radiopharmaceuticals for the patients. Part of this shield used a very thick ordinary glass since 'lead glass' required for such shielding was not available in the country. Recently this bench shield was replaced by a commercially available one 
which had a proper 'lead glass'. The aim of this study was to assess the improvement provided through this change.

\section{Materials and Methods}

The in-house fabricated table top bench shield was made in the form of a cubic block with a base of $400 \mathrm{~mm} \times 400 \mathrm{~mm}$. It had an almost cubic cavity in the middle, open to the top, such that the side wall had a thickness of $152.4 \mathrm{~mm}$. The radiation sources are kept in this cavity while handled. An ordinary glass of size $250 \mathrm{~mm} \times 250 \mathrm{~mm}$, with a thickness of $254 \mathrm{~mm}$ was fixed at one of the top edges of the lead base at an inclined angle. This provided a shielded viewing window.

The commercial table top shield which replaced the above recently had a design as shown in Figure 1. It basically consisted of an L-shaped thick lead structure with an inclined glass shield at the top, to make a viewing window. The glass shield, $300 \mathrm{~mm} \times 400 \mathrm{~mm}$ in area, constitutes of a single panel of lead-glass, which is equivalent to $2.2 \mathrm{~mm}$ thickness of lead. The front and base barrier were constructed from $10 \mathrm{~mm}$ of lead inbuilt spill tray. The radiation trefoil label indicated a base dimension of $300 \mathrm{~mm} \times 400 \mathrm{~mm}$. Extra lead blocks are usually placed on the sides of the base to protect people working on the two sides of the table-top bench shield.

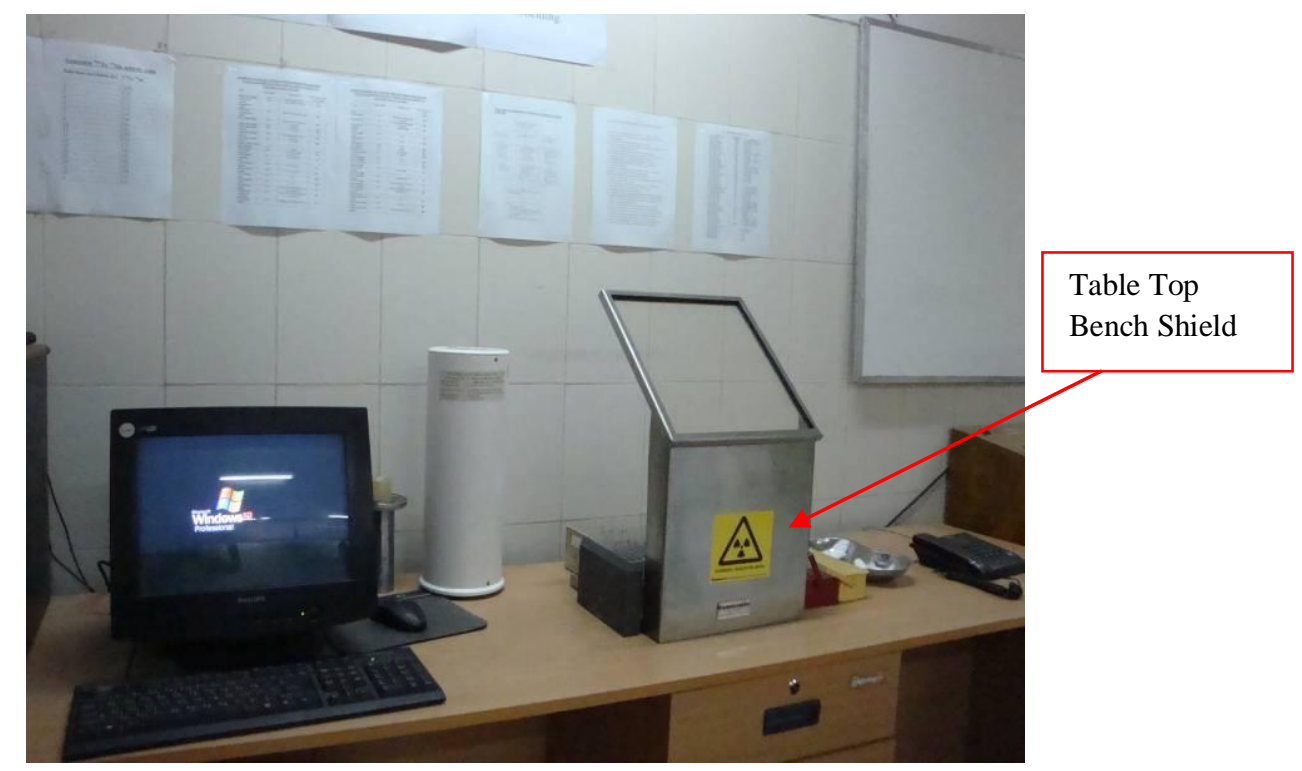

Figure 1: A commercial table top bench shield

Two nuclear medicine technologists were given one additional TLD besides their own TLD and wore the TLD for two months on their apron collar. For two months they worked with the in-house (homemade) table top bench shield. Before their next rotation the shield was replaced by the commercially procured table top bench shield, and again, with different TLD for each technologist. Measurements were taken over another two month period.

To compare the shielding provided we took two $100 \mu \mathrm{Ci}$, Tc-99m radiation sources, taken in syringes, and placed these at $0 \mathrm{~mm}, 5 \mathrm{~mm}, 10 \mathrm{~mm}$, and $20 \mathrm{~mm}$ distance from the inclined glass shield, away from the user, in both the designs. We placed the sensor of a Geiger counter (survey meter) on the outer surface of the glass shields and took measurements for all the above source distances. Similar measurements were taken for the lead walls at the lower side of both the shields. The results are presented below. 


\section{Results and Observations}

The radiation exposures received by the two technologists (user-1 and user-2) over the two 2-month periods are presented in Table-1. A significant difference was observed for both users due to changing of the bench shield. For user 1 the exposure dropped from $0.937 \mathrm{mSv}$ for the old shield to $0.292 \mathrm{mSv}$ for the new shield, while for user 2, the exposure dropped from $1.098 \mathrm{mSv}$ to $0.187 \mathrm{mSv}$ for the same change in the shield.

The results of the survey meter comparison for two similar sources placed at distances of $5 \mathrm{~cm}, 10 \mathrm{~cm}$ and $20 \mathrm{~cm}$ from the two types of table top bench shields are presented in Table 2. It shows that for the lead walls in the bottom section, there is no significant difference of radiation dose rate between the two but the difference is very much significant for the glass window. With the source at the surface of the glass window, the reduction was from $332 \pm 30.5 \mu \mathrm{Sv} / \mathrm{h}$ for the ordinary glass of the home-made shield to $26.95 \pm 8.20 \mu \mathrm{Sv} / \mathrm{h}$ for the lead glass of the commercial shield. With the source placed at a distance of $20 \mathrm{~cm}$ the dose rate reduced from $50 \pm 9.22 \mu \mathrm{Sv} / \mathrm{h}$ to $3.10 \pm 0.55 \mu \mathrm{Sv} / \mathrm{h}$.

Table 1: Individual Radiation Exposure (External) Report

\begin{tabular}{lcc}
\hline User & $\begin{array}{c}\text { Old table top bench shield } \\
\text { Effective Dose }(\mathbf{m S v})\end{array}$ & $\begin{array}{c}\text { New table top bench shield } \\
\text { Effective Dose }(\mathbf{m S v})\end{array}$ \\
\hline User 1 & 0.937 & 0.292 \\
User 2 & 1.098 & 0.187 \\
\hline
\end{tabular}

Table 2: Reading at different locations and distances of old and new table top bench shields for the same source

\begin{tabular}{cccc}
\hline Location & Distance & $\begin{array}{c}\text { Old Table Top Bench Sheild } \\
\text { Dose Rate }(\mu \mathrm{Sv} / \mathrm{h}) \\
{[\text { Mean value } \pm \text { SD }]}\end{array}$ & $\begin{array}{c}\text { New Table Top Bench Sheild } \\
\text { Dose Rate }(\mu \mathrm{Sv} / \mathrm{h}) \\
{[\text { Mean value } \pm \text { SD }]}\end{array}$ \\
\hline $\begin{array}{c}\text { At the glass } \\
\text { window }\end{array}$ & At surface & $332 \pm 30.5$ & $26.95 \pm 8.20$ \\
& 5 & $184 \pm 25.8$ & $10.50 \pm 4.22$ \\
& 10 & $127 \pm 20.5$ & $8.30 \pm 3.15$ \\
At the & 20 & $50 \pm 9.22$ & $3.10 \pm 0.55$ \\
lead wall & At surface & $0.74 \pm 0.36$ & $0.81 \pm 0.45$ \\
& 5 & $0.66 \pm 0.21$ & $0.72 \pm 0.40$ \\
& 10 & $0.53 \pm 0.18$ & $0.61 \pm 0.34$ \\
& 20 & $0.41 \pm 0.12$ & $0.53 \pm 0.20$ \\
\hline
\end{tabular}

\section{Discussion and Conclusion}

The responsibilities of the radiation control officer or concerned person working in nuclear medicine is to ensure the safe and efficient operation of the hot-lab facility. Local and international legislation set out radiation exposure limits, i.e. they set the ceiling. We should, therefore, always bear in mind the concept of "As Low As Reasonably Achievable" (ALARA). If the exposure of operational personnel can be minimized reasonably, it should be done so. Laboratory infrastructure that ensures radiation safety, as well as the awareness and understanding of scientific/technical 
personnel, contributes to minimizing exposure risk. Each component should be reviewed periodically to ensure that latest developments and techniques are being applied to minimize radiation exposure. Therefore, the design features of the hot-lab facility should also be revisited and any design element that can be improved at a reasonable cost should be implemented. Designing devices for radiation protection must take into account the paramount issue of radiation protection. While initiative for indigenous devices should be encouraged, such devices should adhere to all international bench marks of efficiency and safety.

Hot-lab is the main source of radiation in a nuclear medicine department. The table top bench shield, where the nuclear medicine staff prepares and dispenses the radiopharmaceutical for patients of different types of studies with a range of radionuclide activity is the major source of radiation exposure.

Our department initially did not procure a table top bench shield or body shield, instead an indigenous table top bench shield was constructed by the Institute's personnel. Its upper window was made of $254 \mathrm{~mm}$ thick ordinary glass because lead glass is not available in our country. Although such a large thickness of glass reduced the radiation to a safe level, viewing was difficult for the nuclear medicine technologists. The present work shows that with the old plain glass shield technicians received 3 to 5 times the dosage compared to that with the new commercial shield. Although the dosage was high, through a schedule of work rotation we ensured that the annual cumulative dose of exposure received by a technician does not exceed the safe limits.

During measurement with a survey meter, the measurements were carried out simultaneously using two syringes with sources of the same activity so that the data could be compared with reliability.

Both the results show that exposure to the upper part of the technicians' body was successfully minimized by changing the bench shield to a commercially available one with a lead glass window.

\section{Acknowledgements}

The authors would like to thank the Institute of Nuclear Medicine \& Ultrasound, Bangladesh Atomic Energy Commission, for its kind permission to use the laboratories to do the research work. The authors also wish to acknowledge the Abdus Salam International Centre for Theoretical Physics (ICTP), Trieste, Italy, for financial and logistic support to Dr. Kamila Afroj Quadir during her visit. This work was partly carried out within the framework of the Associateship Scheme of ICTP.

\section{References}

1. Occupational Radiation Protection. IAEA Safety Standards Series No. Rs-G-1.3, 1999.

2. Ionising Radiations Regulations - A Guide for Radiation Protection Supervisors, 1999. http://www.radman.co.uk/resources/IRR99-ionising-radiation-regulations.aspx

3. Occupational radiation exposure, US Nuclear Regulatory Commission, Washington, DC, US Government Printing Office. NUREG-0714, p: 12-13, 1997.

4. Hendee, W., and Lohlein, S,: Handling therapeutic doses of radioactive nuclides in a hospital, Radiol.Technol. 40:81, 1968.

5. International Commission on Radiological Protection: Report of Committee V (1953 - 62): Handling and Disposal of Radioactive Materials in Hospitals and Medical Research Establishments, ICRP publ.5, Pergamon Press (New York), 1964.

6. International Commission on Radiological Protection: Protection of the Patients in Radionuclide Investigations, ICRP publ. 17, Pergamon Press (New York), 1971.

7. Recommendations of the International Commercial on Radiological Protection, Annals of the ICRP (ICRP60), Vol.21 (1-3), Pergamon Press (New York), 1990. 